\title{
Dampak Pola Asuh Otoriter Terhadap
}

Perkembangan Remaja

\author{
Irna Ireni Tasuab \\ Sekolah Tinggi Agama Kristen Terpadu PESAT Salatiga
}

irna08tasuab@gmail.com

\begin{abstract}
Adolescence is a period of transition from childhood to adulthood. Where teenagers cannot be said to be children anymore, but physically, teenagers cannot be said to be adults. At this stage parental warfare and parenting are very important to support the growth and development of adolescents. How parents raise children will determine who he is as a teenager. The purpose of this study was to determine the impact of authoritarian parenting on adolescent development. Research on the Impact of Authoritarian Parenting on Adolescent Development uses the Library Research method. The library research method is a data collection technique in the form of notes, books, papers or articles, journals and so on. The results of this study are authoritarian parenting is very influential on adolescent development. Where the negative impact outweighs the positive impact.
\end{abstract}

\begin{abstract}
Abstrak
Remaja adalah masa transisi dari kanak-kanak menjadi dewasa. Dimana remaja tidak bisa dikatakan anak-anak lagi, tetapi secara fisik remaja belum bisa dikatakan dewasa. Pada tahap ini perang orang tua dan pola pengasuhan sangat penting untuk mendukung pertumbuhan dan perkembangan remaja. Seperti apa orang tua mengasuh anak akan menentukan siapa dirinya ketika remaja. Tujuan dari penelitian ini untuk mengetahui dampak dari pola asuh otoriter terhadap perkembangan remaja. Penelitian tentang Dampak Pola Asuh Otoriter Terhadap Perkembangan Remaja mengunakan metode penelitian Studi Kepustakaan (Library Research). Metode penelitian kepustakaan merupakan teknik pengumpulan data yang berupa catatan, buku, makalah atau artikel, jurnal dan sebagainya. Hasil dari penelitian tersebut adalah pola asuh otoriter sangat berpengaruh terhadap perkembangaan remaja. Dimana dampak negatif lebih banyak dari dampak positifnya.
\end{abstract}

\section{Kata Kunci: Pola Asuh, Otoriter, Remaja.}




\section{Pendahuluan}

Pertumbuhan seorang anak bergantung pada gaya/ cara mendidik kedua orang tua yang diterima sejak dilahirkan. Kedua orang tua merupakan guru pertama bagi remaja. Oleh karenanya, cara pendidikan dan bimbingan dalam mendidik anakanak dapat memberi kesan kepada perkembangan remaja. ${ }^{1}$ Cara bimbingan orang tua terhadap anak ada tiga seperti yang dikemukan oleh Baumrid yaitu Otoriter, Primisif dan Demokratis. Orang tua juga berperan penting dalam membangun disiplin kerohanian anak sehingga menolong pertumbuhannya ketika menjadi remaja. Seperti yang dikatakan oleh Simamora dan Hasugian dalam tulisannya Santosa bahwa orang tua berperan penting dalam menanamkan nilai kekristenan dalam diri anak. Santosa juga mengatakan bahwa dalam menankan nilai kekristenan harus dilakukan secara berulangulang dalam keadaan apa pun berdasarkan kajian Ulangan 6:6-9. ${ }^{2}$

Menurut Darling dan Sternberg dalam tulisannya Fildzah Rudyah mengatakan bahwa Pola pengasuhan orang tua merupakan kumpulan sikap, perilaku orang tua, dan pola interaksi antara anak dan orang tua yang berperan dalam membentuk kepribadian anak $^{3}$. Baumrind mengelompokkan pola asuh orangtua ke dalam tiga kategori yaitu pola asuh otoriter, demokratis, dan permisif dalam tulisannya ${ }^{4}$. Menurut Baumrind dalam tulisannya Dwi Karunia Saputra dan Dian Ratna Sawitri pola asuh otoriter adalah gaya pengasuhan yang membatasi dan bersifat menghukum yang mendesak anak untuk mengikuti petunjuk orang tua dan untuk menghormati pekerjaan

${ }^{3}$ Fildzah Rudyah Putri1, "HUBUNGAN POLA ASUH OTORITER TERHADAP PERILAKU PERUNDUNGAN PADA REMAJA," Jurnal Kesejahteraan Keluarga dan Pendidikan (n.d.).

${ }^{2}$ Santosa Santosa, "Urgensi Peran Orang Tua Membangun Kepemimpinan Anak Di Era Disrupsi Teknologi Berdasarkan Ulangan 6: 6-9," EDULEAD: Journal of Christian Education and Leadership 2, no. 1 (June 1, 2021): 71-88, https://stak-pesat.ac.id/e-

journal/index.php/edulead/article/view/61.

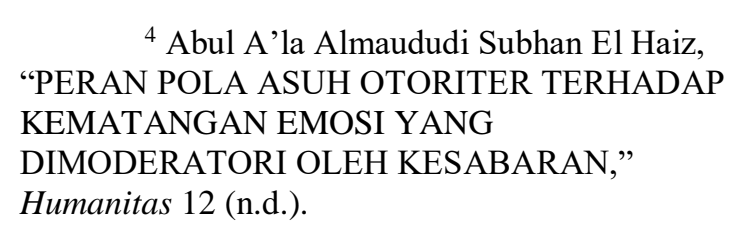

${ }^{4}$ Abul A'la Almaududi Subhan El Haiz, "PERAN POLA ASUH OTORITER TERHADAP KEMATANGAN EMOSI YANG DIMODERATORI OLEH KESABARAN," Humanitas 12 (n.d.). 
dan usaha. ${ }^{5}$ Menurut Baumrind dalam tulisan Eli Rohaeli Badria Pola asuh demokratis adalah pola asuh yang memprioritaskan kepentingan anak, akan tetapi tidak ragu-ragu mengendalikan mereka. Orang tua tipe ini juga bersikap realistis terhadap kemampuan anak, tidak berharap berlebihan yang melampaui kemampuan anak dan memberikan kebebasan kepada anak untuk memilih dan melakukan suatu tindakan. ${ }^{6}$ Pola Permisif adalah membiarkan anak bertindak sesuai dengan keinginannya, orang tua tidak memberikan hukuman dan pengendalian. Menurut Saedah Siraj pola asuh yang paling tepat bagi orang tua untuk mendidik anak adalah pola asuh demokratis yang merupakan bisa memberikan kebebasan kepada anak dan juga memberikan batasan kepada anak. ${ }^{7}$ Menurut Anjar Muhmadi pola asuh otoriter mempunyai arti

${ }^{5}$ Dian Ratna Sawitri Dwi Karunia Saputra, "POLA ASUH OTORITER ORANG TUA DAN AGRESIVITAS PADA REMAJA PERTENGAHAN DI SMK HIDAYAH SEMARANG," Jurnal Empati Volume 4 (2015).

${ }^{6}$ Wedi Fitriana Eli Rohaeli Badria, "POLA ASUH ORANG TUA DALAM MENGEMBANGKAN POTENSI ANAK berkuasa sendiri, sewenangwenangnya. Sedangkan menurut Barnodib otoriter adalah pemegang peran orang tua, semua kekuasaan adapanya, dan keaktifan anak ditentukan olehnya, anak sama sekali tidak mempunyai hak untuk mengemukakan pendapat. $^{8}$ Dari definisi tersebut di atas, dapat disimpulkan bahwa otoriter merupakan wewenang atau hak anak sepenuhnya ditentukan oleh orang tua.

Menurut Yuliyanti Bun Pola asuh otoriter adalah pola asuh yang merupakan kebalikan dari pola asuh demokratis yaitu cenderung menetapkan standar yang mutlak harus dituruti, biasanya disertai dengan ancaman-ancaman. Menurut Bumrind pola asuh otoriter adalah suatu bentuk pola asuh yang menuntut agar anak patuh dan tunduk terhadap semua perintah dan aturan yang dibuat oleh orang tua tanpa ada

\section{MELALUI HOMESHOOLING DI KANCIL CENDIKIA," JURNAL COMM-EDU 1 (2018). \\ ${ }^{7}$ Siraj, Psikologi Perkembangan Anak Dan} Remaja, Hal. 169.

${ }^{8}$ Anjar Muhmadi Nusation, Sikap Otoriter Orang Tua Dan Dampaknya Terhadap Emosional Anak (Yogyakarta: Bintang Pustaka, 2020), hal. 3. 
kebebasan untuk bertanya atau mengemukakan pendapat sendiri. ${ }^{9}$ Jadi, dari definisi tersebut dapat disimpulkan bahwa pola asuh otoriter merupakan bentuk pengasuhan dengan banyak atauran yang disertai dengan ancaman-ancaman agar patuh dan tunduk pada apa yang diinginkan oleh orang tua.

Menurut Steve remaja merupakan masa transisi, suatu tahap yang canggung ditengah-tengah masa kanak-kanak dan masa remaja. Sedangkan definisi dari Oxford English Dictionary tentang kata adole scent sangat tepat: diantara anak-anak dan orang dewasa. Mereka bukan lagi anak-anak, tetapi mereka juga belum selesai ber-metamorfosis menjadi orang dewasa yang matang. ${ }^{10}$

Masa remaja merupakan masa transisi. Proses transisi ini, remaja melalui banyak perubahan yang menjadi penyebab remaja merasa tertekan. Dalam perkembangan remaja, banyak terjadi perubahan

\footnotetext{
${ }^{9}$ Dewi Mufidatul Ummah Yuliyanti Bun, Bahran Taib, "Analisis Pola Asuh Otoriter Orang Tua Terhadap Perkembangan Moral Anak," Jurnal Pendidikan Guru Pendidikan Anak Usia Dini 3 (2020).

${ }^{10}$ Steve Chalke, Awas Anak-Anak Sudah Remaja (Yogyakarta: ANDI, 2007), hal. 9.
}

fisik dan motorik yang dikaitkan dengan kematangan atau akil balik, perkembangan kognitif dan intelektual, perkembangan sosial dan perkembangan emosi. Menurut Suizzo dalam buku Psikologi Perkembangan Anak dan Remaja, dalam masa perkembangan fungsi kognitif dan fungsi emosi saling bertindak keatas atau satu sama lain dalam meningkatkan kemampuan untuk memikirkan dan memahami emosi sendiri, mempertimbangkan perspektif orang lain, dan merancang suatu tindakan ${ }^{11}$.

Geloman dalam buku Psikologi Perkembangan Anak dan Remaja mengatkan bahwa kehidupan dalam keluarga adalah sekolah pertama bagi pembelajaran emosi dimana anak-anak belajar mengatur pelajaran diri sendiri dan bagaimana reaksi orang lain terhadap dirinya, bagaimana berpikir mengenai perasaannya, reaksi yang dipilih, bagaimana mengekspresikan dan

\author{
${ }^{11}$ Saedah Siraj, Psikologi Perkembangan \\ Anak Dan Remaja (Bandung: PT Remaja \\ Rosdakarya, 2020), hal. 119.
}


menggambarkan ketakutan serta harapan. Oleh karena itu, komunikasi orang tua dengan anak sangat memberi dampak yang besar terhadap anak-anak. Baumrind menyatakan bahwa Remaja yang mendapatkan gaya pengasuhan otoritarian bersifat tidak gembira, bimbang, mempunyai keyakinan diri yang rendah, tidak bisa berdikari, kurang inisiatif, kurang mampu dalam bersosial dan kurang mampu dalam bersosial. ${ }^{12}$

Menurut penulis berdasarkan hasil penelitian di atas, menyatakan bahwa pola asuh otoriter merupakan gaya pengasuhan yang digunakan oleh orang tua terhadapa anaknya, didalamnya ada banyak atauran yang disertai dengan ancaman-ancaman agar anak patuh dan tunduk pada apa yang diinginkan oleh orang tua Remaja merupakan masa peralihan dari masa kanak-kanak ke masa dewasa. Dimana pada fase tersebut, tidak lagi disebut anak-anak dan juga secara fisik belum dewasa.
Berdasarkan uraian yang telah disampaikan peneliti di atas, maka hipotesis yang diajukan adalah dampak dari pola asuh otoriter terhadap perkembangan remaja.

\section{Metode Penelitian}

Untuk mengetahui dampak dari pola asuh otoriter terhadap terhadap perkembagana remaja, maka peneliti menggunakan metode atau pendekatan berupa Studi Kepustakaan (Library Research). Menurut Mardalis suatu studi yang digunakan dalam mengeumpulkan informasi dan data dengan bantuan berbagai macam material yang ada di perpustakaan seperti dokumen, buku, majalah, kisah-kisah sejarah $^{13}$. Menurut Arikunto metode kepustakaan adalah Teknik pengumpulan data dalam penelitian ini adalah mencari data mengenai halhal atau variabel yang berupa catatan, buku, makalah atau artikel, jurnal dan sebagainya ${ }^{14}$.

\footnotetext{
${ }^{12}$ Siraj, Psikologi Perkembangan Anak Dan Remaja, Hal. 169.

${ }^{13}$ Budi Purwoko Abdi Mirzaqon, “'STUDI KEPUSTAKAAN MENGENAI LANDASAN
}

TEORI DAN PRAKTIK KONSELING EXPRESSIVE WRITING," Jurnal BK Unesa 8, no. 1 (2018): 1-8.

$$
{ }^{14} \text { Ibid. }
$$




\section{Hasil dan Pembahasan}

\section{Pola Asuh}

Tarmuji dalam tulisannya Chintia Wahyuni Puspita Sari menyatakan bahwa Pola asuh merupakan bentuk-bentuk yang diterapkan dalam rangka merawat, memelihara, membimbing/ melatih, dan memberikan pengaruh. ${ }^{15}$ Sedangkan Menurtut Dwiharso dalam tulisan Mardiah, Lisda Yuni dan Syahrul Ismet meyatakan bahwa Pola asuh dan figur orang tua sangatlah penting guna mengarahkan anak mengimani agamanya dan juga mempelajari akhlak dan pekerti. Apabila ada kesalahan dalam proses pengasuhan terhadap anak maka, akan berdampak terhadap perkembangan anak secara fisik maupun psikis $^{16}$. Dari definisi diatas dapat disimpulkan bahwa pola asuh merupakan bentuk/ cara yang diterapkan oleh orang tua terhadap anak dalam membimbing dan membesarkan anak. Baumrind mengelompokkan pola asuh orang tua ke

${ }^{15}$ Chintia Wahyuni Puspita Sari, "Pengaruh Pola Asuh Otoriter Orang Tua Bagi Kehidupan Sosial Anak," JURNAL PENDIDIKAN dan KONSELING Volume 2 (2020).

\footnotetext{
${ }^{16}$ Lisda Yuni Mardiah and Syahrul Ismet, "DAMPAK PENGASUHAN OTORITER TERHADAP PERKEMBANGAN SOSIAL ANAK," JCE (Journal of Childhood Education) 5 (2021).
}

dalam tiga kategori yaitu pola asuh otoriter, demokratis, dan permisif ${ }^{17}$.

\section{Pola asuh otoriter}

Menurut Baumrind pola asuh otoriter merupkan pola asuh yang cenderung menetapkan standar yang mutlak harus dituruti. Orang tua yang mengasuh anaknya dengan pola asuh tersebut cenderung memaksa, memerintah, dan menghukum. Orang tua beranggapan bahwa dengan cara mendidik seperti ini akan membawa dampak yang baik kepada anak ${ }^{18}$.

Dampak pola asuk otoriter Dalam tulisannya Mardiah, Lisda Yuni dan Syahrul Ismet ada Penelitian yang dilakukan oleh (Sari, 2020) menyebutkan bahwa Pengaruh positif Pola Asuh Otoriter Orang Tua Bagi Kehidupan Sosial Anak, cenderung mempunyai tanggung jawab serta kompetensi, tetapi pengaruh negatif pola asuh otoriter banyak anak yang tidak memiliki kepercayaan diri serta

${ }^{17}$ Subhan El Haiz, "PERAN POLA ASUH OTORITER TERHADAP KEMATANGAN EMOSI YANG DIMODERATORI OLEH KESABARAN."

\footnotetext{
${ }^{18}$ Wedi Fitriana Eli Rohaeli Badria, "POLA ASUH ORANG TUA DALAM MENGEMBANGKAN POTENSI ANAK MELALUI HOMESHOOLING DI KANCIL CENDIKIA," JURNAL COMM-EDU Volume 1 (2018).
} 
bersikap menarik diri, anak melawan karena merasa tidak ada peluang atau kebebasan untuk meyampaikan pendapat. ${ }^{19}$ Penelitian kedua yang dilakukan oleh Zukhri dan Suryani dampak negatif dari pola asuh otoriter terhadap anak adalah tidak percaya diri, tidak bisa bergaul dengan teman sebaya dan kurangnya inisiatif ${ }^{20}$. Bumris juga menyatakan dalam tulisannya Saedah bahwa remaja yang mendapatkan pola pengasuhan otoriter memiliki sifat tidak gembira, bimbang, mempunyai keyakinan diri yang rendah, tidak bisa berdikari, kurang inisiatif, kurang bersosialisasi, dan suka melawan. ${ }^{21}$

\section{Pola asuh primisif}

Menurut Wulanda Aditya Azis dalam tulisannya pola asuh primisif merupakan pola pengasuhan yang memberikan kesempatan kepada anak untuk melakukan apa

\footnotetext{
${ }^{19}$ Mardiah and Syahrul Ismet, "DAMPAK PENGASUHAN OTORITER TERHADAP PERKEMBANGAN SOSIAL ANAK."

${ }^{20}$ Ibid.

${ }^{21}$ Siraj, Psikologi Perkembangan Anak Dan Remaja, Hal. 169.
}

saja yang diinginkan oleh anak tanpa pengawasan yang cukup dari orang tua. Wulanda juga mengatakan bahwa pola asuh tersebut juga cenderung tidak mengingatkan anak apabila anak sedang dalam bahaya dan bimbimbingan yang diberikan oleh orang tua juga sedikit sehingga disukai oleh anak ${ }^{22}$.

\section{Dampak dari pola asuh primisif}

Baumrid menyatakan remaja yang mendapatkan pengasuhan primisif akan bersikap mementingkan diri sendiri, tidak bermotivasi, tidak berdikari, implusif menginginkan perhatian dan tidak mendengarkan nasihat. $^{23}$

\section{Pola asuh demokratis}

Menurut Baumrid dalam tulisannya Eli Rohaeli Badria dan Wedi Fitriana mengatkan bahwa Pola asuh demokratis adalah pola asuh yang memprioritaskan kepentingan anak, akan tetapi tidak ragu-ragu mengendalikan mereka. Orang tua

\footnotetext{
${ }^{22}$ Wulanda Aditya Azis, "PENERAPAN POLA ASUH OTORITER PADA ANAK (Studi Kasus Pada Kader Posyandu Di Desa Kawungluwuk Kecamatan Tanjungsiang Kabupaten Subang)," JURNAL TUNAS SILIWANGI Vol.4 (2018).

${ }^{23}$ Siraj, Psikologi Perkembangan Anak Dan Remaja, hal. 169.
} 
tipe ini juga bersikap realistis terhadap kemampuan anak, tidak berharap berlebihan yang melampaui kemampuan anak dan memberikan kebebasan kepada anak untuk memilih dan melakukan suatu tindakan. Pengaruh pola asuh demokratis akan menghasilkan karakteristik anak yang mandiri, dapat mengontrol diri, mempunyai hubungan baik dengan temantemannya. ${ }^{24}$ Baumrid dalam buku Psikologi Perkembangan Anak dan Remaja menyatakan bahwa remaja yang mendapatkan pola pengasuhan demokratis adalah remaja yang periang, berkeyakinan diri, mempunyai perasaan ingin tahu, berdikari, disukai banyak orang, menghormati orang lain dan sukses disekolah. $^{25}$

\section{Perkembangan Remaja}

Menurut Suizzo dalam buku Psikologi Perkembangan Anak dan Remaja, dalam masa perkembangan fungsi kognitif dan fungsi emosi saling bertindak keatas atau

${ }^{24}$ Eli Rohaeli Badria, "POLA ASUH ORANG TUA DALAM MENGEMBANGKAN POTENSI ANAK MELALUI HOMESHOOLING DI KANCIL CENDIKIA." satu sama lain dalam meningkatkan kemampuan untuk memikirkan dan memahami emosi sendiri, mempertimbangkan perspektif orang lain, dan merancang suatu tindakan ${ }^{26}$. Aspekaspek perkembangan remaja sebagai berikut:

\section{Perkembangan fisik}

Apabila remaja melalui proses kematangan, mereka akan tumbuh besar dengan kematangan seks. Ahli psikologi menyatakan bahwa penting bagi remaja untuk mengetahui tentang proses kematangan ini agar lebih bersedia menjalaninya.

Remaja yang menaglami perkembangan seks terlalu lambat atau awal kemungkinan akan menghadapi gangguan. Contoh, remaja perempuan yang mengalami perkembanggan lebih awal kemungkinan menghadapi kemurungan, penggunaan bahan terlarang, tingkahlaku terganggu, dan gangguan asupan makanan. Perkembangan remaja laki-laki yang tidak asama dengan teman sebayanya

${ }^{25}$ Siraj, Psikologi Perkembangan Anak Dan Remaja, hal. 169. Remaja. 
akan lebih mudah terkena dengan aktifitas seks, merokok dan melarang aturan.

2. Perkembangan kognitif

Pada tahap ini, perkembangan kognitif lebih drastis dibandingkan dengan perkembangan fisik. Remaja mampu membuat analisis logikal terhadap suatu situasi dengan berpikirtentang sebab dan akibat. Remaja berpikir pada tingkat tinggi yang membiasakan berpikir tentang masa depan, mencari alternatif, serta menetapkan tujuan hidup. Remaja laki-laki dan perempuan memiliki kedewasaan kognitif yang berbeda, pada tahap ini remaja perempuan dewasa dalam membaca dan bersosial sedangkan remaja laki-laki dewasa dalam berolahraga dan berlogika. Pada tahap ini orang dewasa perlu menolong remaja agar fokus remja pada salah satu keahliaan berdasarkan sembilan kecerdasan yang dikemukakan oleh Gardner. ${ }^{27}$

3. Perkembangan moral

Perkembangan moral berbicara tentang nilai dan tingkah laku yang bererika. Pada tahap ini, orang tua mampu mengembangkan moral remaja dengan menjadi contoh atau role model yang baik kepada anak remaja. Dengan cara tersebut remaja dapat mempelajari nilai positif dan dapat mempraktikannya dimasa yang akan datang. ${ }^{28}$

4. Perkembangan emosi

Perkembangan emosi berkaitan dengan identitas seseorang saat masa remaja, seseorang akan belajar untuk mengatur emosi yang akan mempengaruhi gaya hidup. Selain itu perkembangan perkembangan identitas juga kembali kepada sesseorang ingin menjadi apa atau siapa dimasa yang akan datang. Terdapat dua konsep identitas yang perlu dipahami:

1. Konsep diri sendiri (possible self) yaitu suatu aset kepercayaan individu tentang diri sendiri,

2. Penghargaan terhadap diri sendiri, yaitu bagaimana membuat penilaian terhadap dirinya (Self Esteem). Oleh karena itu kedua orang tua perlu berhati-

\footnotetext{
${ }^{27}$ Ibid., hal. 123-124.

${ }^{28}$ Ibid., hal. 125.
} 
hati saat berbicara dengan remaja seperti: bertanya yang tidak membahayakan, mendengar tanpa menghukum, bertanya secara terbuka, peka dengan emosi remaja terlebih dahulu, dan selalu berbincang mengenai masalah etika dan moral. ${ }^{29}$

5. Perkembangan sosial remaja

Perkembangan sosial remaja dapat dilihat melalui konteks teman sebaya, keluarga, sekolah, tempat kerja dan komunitas. ${ }^{30}$

6. Perkembangan tingkah laku remaja Setelah terjadi perkembangan kognitif, fisik, sosial, dan emosi remaja akan mencoba tingkah laku yang baru. Percobaan atau uji kaji tingkah laku ini membantu perkembangan tingkah laku remaja dalam berbagai suasana. Remaja yang suka tingkah laku berisiko dapat membentuk identitas remaja dalam membuat keputusan, dan belajar membuat penilaian yang lebih realistis terhadap orang lain. Namun kadang kala remaja yang mencobacoba ini akan menghadapi tingkah laku buruk terhadap tingkah lakunya ${ }^{31}$.

\section{Kesimpulan}

Berdasarkan hasil penelitian diatas, dapat disimpulkan bahwa pengasuhan orang tua sangat penting bagi perkembangan remaja. Pola asuh yang digunakan orang tua sangat berdampak terhadap perkembangan remaja. Berdasarkan penelitian tersebut, penulis mendapatkan hasil bahwa pola asuh otoriter memberi dampak positif dan negatif terhadap perkembangan remaja, dampakdampak dari pola asuh otoriter sangat berpengaruh pada perkembangan psikis remaja. Dari hasil penelitian tersebut terbukti bahwa dampak negatif dari pola asuh otoriter lebih banyak dari pada dampak positifnya.

\footnotetext{
${ }^{29}$ Ibid., hal. 126-127.

30 Ibid., hal. 132.
}

${ }^{31}$ Ibid., hal. 140. 


\section{DAFTAR PUSTAKA}

Abdi Mirzaqon, Budi Purwoko. “'STUDI

KEPUSTAKAAN MENGENAI

LANDASAN TEORI DAN PRAKTIK

KONSELING EXPRESSIVE

WRITING."” Jurnal BK Unesa 8, no. 1 (2018): 1-8.

Azis, Wulanda Aditya. "PENERAPAN

POLA ASUH OTORITER PADA

ANAK (Studi Kasus Pada Kader

Posyandu Di Desa Kawungluwuk

Kecamatan Tanjungsiang Kabupaten

Subang)." JURNAL TUNAS

SILIWANGI Vol.4 (2018).

Chalke, Steve. Awas Anak-Anak Sudah

Remaja. Yogyakarta: ANDI, 2007.

Dwi Karunia Saputra, Dian Ratna Sawitri.

"POLA ASUH OTORITER ORANG

TUA DAN AGRESIVITAS PADA

REMAJA PERTENGAHAN DI SMK

HIDAYAH SEMARANG.” Jurnal

Empati Volume 4 (2015).

Eli Rohaeli Badria, Wedi Fitriana. "POLA

ASUH ORANG TUA DALAM

MENGEMBANGKAN POTENSI

ANAK MELALUI HOMESHOOLING

DI KANCIL CENDIKIA.” JURNAL

COMM-EDU 1 (2018).

“POLA ASUH ORANG TUA
DALAM MENGEMBANGKAN

POTENSI ANAK MELALUI

HOMESHOOLING DI KANCIL

CENDIKIA." JURNAL COMM-EDU

Volume 1 (2018).

Mardiah, Lisda Yuni, and Syahrul Ismet.

"DAMPAK PENGASUHAN

OTORITER TERHADAP

PERKEMBANGAN SOSIAL ANAK."

JCE (Journal of Childhood Education)

5 (2021).

Nusation, Anjar Muhmadi. Sikap Otoriter

Orang Tua Dan Dampaknya Terhadap

Emosional Anak. Yogyakarta: Bintang

Pustaka, 2020.

Putri1, Fildzah Rudyah. "HUBUNGAN

POLA ASUH OTORITER

TERHADAP PERILAKU

PERUNDUNGAN PADA REMAJA."

Jurnal Kesejahteraan Keluarga dan

Pendidikan (n.d.).

Santosa, Santosa. "Urgensi Peran Orang Tua Membangun Kepemimpinan Anak Di Era Disrupsi Teknologi Berdasarkan Ulangan 6: 6-9." EDULEAD: Journal of Christian Education and Leadership 2, no. 1 (June 1, 2021): 71-88.

https://stak-pesat.ac.id/e-

journal/index.php/edulead/article/view/ 61. 
Sari, Chintia Wahyuni Puspita. "Pengaruh

Pola Asuh Otoriter Orang Tua Bagi

Kehidupan Sosial Anak.” JURNAL

PENDIDIKAN dan KONSELING

Volume 2 (2020).

Siraj, Saedah. Psikologi Perkembangan

Anak Dan Remaja. Bandung: PT

Remaja Rosdakarya, 2020.

—. Psikologi Perkembangan Anak Dan

Remaja. Edited by PT Remaja

Rosdakarya. Bandung, 2020.

Subhan El Haiz, Abul A'la Almaududi.

"PERAN POLA ASUH OTORITER

TERHADAP KEMATANGAN

EMOSI YANG DIMODERATORI

OLEH KESABARAN." Humanitas 12

(n.d.).

Yuliyanti Bun, Bahran Taib, Dewi

Mufidatul Ummah. "Analisis Pola

Asuh Otoriter Orang Tua Terhadap

Perkembangan Moral Anak.” Jurnal

Pendidikan Guru Pendidikan Anak

Usia Dini 3 (2020). 